INTERNATIONAL JOURNAL OF MULTidisciplinARY RESEARCH AND ANALYSis

ISSN(print): 2643-9840, ISSN(online): 2643-9875

Volume 05 Issue 01 January 2022

DOI: 10.47191/ijmra/v5-i1-03, Impact Factor: 6.072

Page No.- $18-23$

\title{
Theses and Dissertations Abstract E-Archiving System with SMS Support
}

\section{Bella Gertrude B. Alpasan}

Institute of Information and Computer Studies, NORTHERN ILOILO POLYTECHNIC STATE COLLEGE Main Campus, Estancia, Iloilo

ABSTRACT: The NIPSC Library is currently using manual-based in keeping the theses and dissertation in order to save more time and easy way of finding related literature, an alternative solution to solve the current problem was developed. The "Theses and Dissertations Abstract E-Archiving System with SMS Support", a system provides borrowers with real-time information in finding related literature. The architectural design used in this system is $\mathrm{N}$-tier architecture. Since it is connected to the Local Area Network inside the library, the researchers can easily access the resources in wired and wireless network to help the Librarians and the researchers inside and outside the library to access the electronic archiving, the collections of abstract theses and dissertations in wired and wireless network to view, download in jpeg format for the protection of copyright and IPR law which can be printed in real-time. The developed Theses and Dissertations Abstract E-Archiving System with SMS Support was based on the result and findings of surveys, electronic archiving of theses and dissertations were accessible just in time, the developed system can perform its required functions efficiently while sharing a common environment and resources without detrimental the impact on any other product.

KEYWORDS: Theses, Dissertations, Abstract, E-Archiving System, SMS Support

\section{INTRODUCTION}

The increased sophistication and availability of technology in daily life have changed the expectations of library users which demand remote access to full-text resources including theses and dissertations. The convergence of technology, open source initiatives, and emerging new paradigm on intellectual property rights have encouraged Electronic Theses and Dissertations (ETDs) projects. NIPSC Library is currently using manual-based in keeping the theses and dissertations. In order to save more time and easy way of finding related literature, an alternative solution to solve the current problem. The system provides borrowers with real-time information in finding related literature. The architectural design used in this system is $\mathrm{N}$-tier architecture, a Short Message Service (SMS) Support, will also be used, as the additional feature which will play a vital role as a communicating tool, to accommodate and provide researchers from external campuses that needs assistance from NIPSC Library Main Campus Estancia, lloilo in finding related literature of their researches. This application can further be enhanced by adding various features to it like we can send and receive various information regarding students on a cell over the air (OTA). Even students can view their assignments on the mobile phone by just using certain services that can be availed from the server. The scope of Project is limited to the use of GSM protocol while sending and receiving the message from the application (Singh and Kumar, 2011). The purpose of this paper is to conduct a literature review looking at the evolution of bibliographic control and access to theses and dissertations including (ETDs) initiatives and the identification of persistent issues and concerns on the implementations of ETDs projects. This feature makes SMS message scheduling possible across all SMS gateways including those that do not internally support scheduling. Moreover, users can also cancel any scheduled message if it is needed (Olaleye1, Olaniyan, Eboda1 and Awolere, 2013).

\section{OBJECTIVES}

- Develop a system wherein all the compilation of abstract of Theses and Dissertations can be easily viewed, downloaded in wired and wireless network with two-way interactive text messaging from inquiries via mobile phone that will provide and respond to a specified text format. 


\section{Theses and Dissertations Abstract E-Archiving System with SMS Support}

- Determine the level of usability of the proposed Theses and Dissertations Abstract E-Archiving System with SMS Support among the identified users group.

- Evaluate the performance of the proposed Theses and Dissertations Abstract E-Archiving System with SMS support in terms of functionality, reliability and efficiency.

\section{Automatic Response System Using SMS}

The paper presents a novel method to send SMS through mobile at the remote host on a mobile service as well for internet host. The method was based on the reliability of the software e-corporate. The system used a specified code, which was being used to access a database system. The data residing the code will be immediately sent to the user regarding which the request had been sent. The utility of the work enhances the educational system to the various business unit.

The reasons for the enormous popularity of SMS have been the fact that this mechanism of sending and receiving messages not only saves time but costs less as well. The advantage for network operators has been the ease of deploying equipment from any vendors that implement the standard. Like other cellular standards. The above developed and developed application is a mobile application for adding values to an institution. This application can only run on the cell phone having GPRS enabled services with them. This application can further be enhanced by adding various features to it like we can send and receive various information regarding students on a cell over the air (OTA). Even a student can view their assignments on the mobile phone by just using certain services that can be availed from the server. The scope of Project is limited to the use of GSM protocol while sending and receiving the message from the application (Singh and Kumar, 2011).

\section{SMS-Based Event Notification System}

Existing mass Short Message Service (SMS) mailing systems are designed to work with a specific SMS gatewayhence resulting in user lock-in to an SMS vendor. Also, some SMS gateways support scheduling of SMS message to be sent at a later time and date, others do not support it. Moreover, those gateways that support scheduling don't mostly allow users to cancel scheduled SMS message. This study has successfully designed and developed an enterprise-class mass SMS mailing system that supports multiple users as well as multiple SMS gateways, providing a unified interface and common set of features across many SMS gateways which prevent vendor lock-in as users can choose among multiple SMS vendor gateways. Another major feature provided by the new system is the introduction of SMS message scheduling. This feature makes SMS message scheduling possible across all SMS gateways including those that do not internally support scheduling. Moreover, users can also cancel any scheduled message if it is needed (Olaleye1, Olaniyan, Eboda1 and Awolere, 2013).

\section{E-Diss.Ch: collecting and archiving online theses at the Swiss National Library}

"e-Diss.ch" is a project undertaken in collaboration with the Swiss university libraries as part of the e-Helvetica project at the Swiss National Library. The mission of the Swiss National Library is to collect and archive all Swiss publications, both printed and electronic. The objective of the e-Helvetica project is to fulfill this mission for electronic publications. The goal of the e-Diss.ch project is to set up a collection of all Swiss online theses and to preserve them in the Digital Archive of the Swiss National Library. In collaboration with several Swiss university libraries, we have designed and tested a shared workflow for the collection, cataloging, archiving and dissemination of online theses. Standards are used to ingest the publications into the Digital Archive of the Swiss National Library, to describe the publications in the catalog, and to identify the publications within the Digital Archive (URN on the basis of NBN). Furthermore, a policy is being developed for the assignment of URN-NBN in the entire Swiss academic domain. This paper gives some general information on the e-Helvetica project and how the Digital Archive is being built at the Swiss National Library. The approach was chosen for the collection, cataloging and dissemination of the online theses will be highlighted as well as the creation of a social infrastructure of the Swiss university libraries and other partners (Barbara Signori, 2014).

\section{Electronic Theses \& Dissertations (ETDS) A Literature Review}

The increased sophistication and availability of technology in daily life have changed the expectations of library users which demand remote access to full-text resources including theses and dissertations. The convergence of technology, open source initiatives, and emerging new paradigm on intellectual property rights have encouraged Electronic Theses and Dissertations (ETDs) projects. The purpose of this paper is to conduct a literature review looking at the evolution of bibliographic control and access to theses and dissertations including (ETDs) initiatives and the identification of persistent issues and concerns on the implementations of ETDs projects. The management and access to thesis literatureat the University of Puerto Rico, Rio Piedras Campus is also covered (Rodriguez, 2016).

In the present study, the system provides the capability to analyze problems related to the day to day operations of the school library particularly in the office of the librarian. 


\section{Theses and Dissertations Abstract E-Archiving System with SMS Support}

\section{Copyright and Intellectual Property Rights}

Copyright and Intellectual Property Rights (IPR) are concerns for those institutions establishing e-theses repositories and the authors who are providing the content. ETDs and paper theses and dissertations are afforded equal copyright protection under the law, regardless of the author's nationality or domicile, and whether or not the copyright is registered (Fineman, 2003). Students, professors and administrators at the English and History Departments opposed Ohio State University plan to put dissertations online. While the University claimed the policy conforms to the University's mission, students and administrators objecting the policy say that posting the documents online could reduce student's chances of publishing the dissertation in journal or university presses, with the implication of whether that was going to take control of the copyright out of the hands of the students and into the hands of the university (Carlson, 2003). Referring to The United Kingdom (UK) Copeland, lists several developments which offer help in clarifying the route to follow regarding IPR, among these are the increase in the availability of advice and an increased awareness of the need for students to understand the IPR issue (Copeland et al, 2005). Andrew's paper on the intellectual property of e-theses examines ownership of copyright within theses, the rights and responsibilities of authors, institutions, end users, and third parties regardless the medium of publication for theses and dissertations. It includes several useful appendices that state legal requirements for publication of e-theses. This paper, although written from the point of view of the United Kingdom IPR laws, applies in many ways to the United States IPR laws. The UK also has the equivalent of "Fair use" of the US Copyright law which is called "fair dealing" and many uses of e-theses are protected by the "fair dealing"(Andrew, 2014).

This literature review revealed that problems encountered by many libraries such as poor technological support, cost control, copyright and preservation issues, and the need for changes in institutional culture were also reported by other institutions. However, there are "many researchers, universities and libraries [which] view ETDs not only as a wave of the future but a tsunami that we have no choice but to ride" (Beaven, 2014). The implementation of an ETD project is certainly a concern for even larger academic libraries in Puerto Rico but it is also a hope to improve access to thesis literature. If the goal is to improve the access and availability of thesis literature by taking advantage of current technological advances, the University of Puerto Rico-Rio Piedras Campus should consider the usage patterns of thesis literature, material obsolescence level by discipline, and the strong tendency of graduate students to use current research, the increase of the incorporation of multimedia into thesis literature, and the need for preservation of this type of material. Furthermore, it must consider the current administrative structure of the libraries on the campus, and the level of technological support for libraries. Ideally, it must strive to provide a uniform, consistent and predictable way to manage thesis literature providing access to current as well as old literature, accommodating the new multimedia formats and complying with current copyright and intellectual property rights. If an ETD project is initiated at the University of Puerto Rico it is important to keep in mind the following points to facilitate the process:

- The ETD initiative must be a collaborative project involving all the libraries at the University of Puerto Rico, Río Piedras Campus and the Office of the Dean of Graduate Studies and Research.

- Education on academic honesty and intellectual property rights must be provided to the university community.

- The project should be flexible taking into consideration the concerns of students, providing training for students on the use of technology for submission of theses.

- The University of Puerto Rico's libraries must provide access and preserve the product of its collective research

- The only proven reliable format for preservation is still microfilm or paper copies

- ETDs are needed to ease access and dissemination of knowledge yet we should not become too dependent on electronic-only options.

- The project must have full administrative support with an adequate budget

- There are advantages and disadvantages of each one of the four different options in dealing with ETDs available to universities (Beaven, 2014).

\section{The Elusive Quest: Software Product Quality Evaluation}

Quality has many definitions and even more models and methods for assurance and evaluation associated with it. After an overview of existing concepts, we provide a comprehensive methodology for evaluating the quality of a software product, complete with methods for model structure and parameter elicitation and a way for mapping the quantitative results obtained from the evaluation to qualitative rankings of product characteristics (e.g. Poor, Good, Excellent). This is complemented with a compendium of quality characteristics and metrics associated with them and a generic quality model combining the works of McCall and Boehm with the international standard for software product quality ISO/IEC 25010. A discussion of the advantages 


\section{Theses and Dissertations Abstract E-Archiving System with SMS Support}

that the use of Bayesian Belief Networks (BBNs) can provide in this framework is also offered, as well as a method for transforming quality models to a form suited for BBN use. The methodology has been applied to a case study (Grigorova, 2010).

\section{METHODOLOGY}

\section{A. Software Development Life Cycle (SDLC)}

The researcher used the Rapid Application Development (RAD) model allowing usable systems to be produced in a short time frame.

The RAD model started with understanding and defining the client's business needs, and moves through the four phases namely; requirements planning phase, the user design phase, the rapid construction phase, and the cutover phase. Testing should involve early in the project and throughout the development effort. One of the goals of RAD is to provide an updated "look and feel" of the evolving product and to allow the client to have hands-on contact with the product as soon as possible.

Throughout these phases, the researcher continually review and update the project plan, carefully controlling all changes requests along the way. Must assess the risks of the project during the completion of each cycle, and review the current understanding of the client's business needs throughout the project.

RAD used a prototyping approach in the software development to help users visualize and request changes to the system as it is being built, allowing applications to evolve iteratively. The objective is to build a feature light version of the finished product in a short amount of time as possible, preferably days or three to four months. The initial prototype serves as a proof of concept for the client, but more importantly, serves as a talking point and tool for refining requirements.

\section{The Rapid Application Development Model}

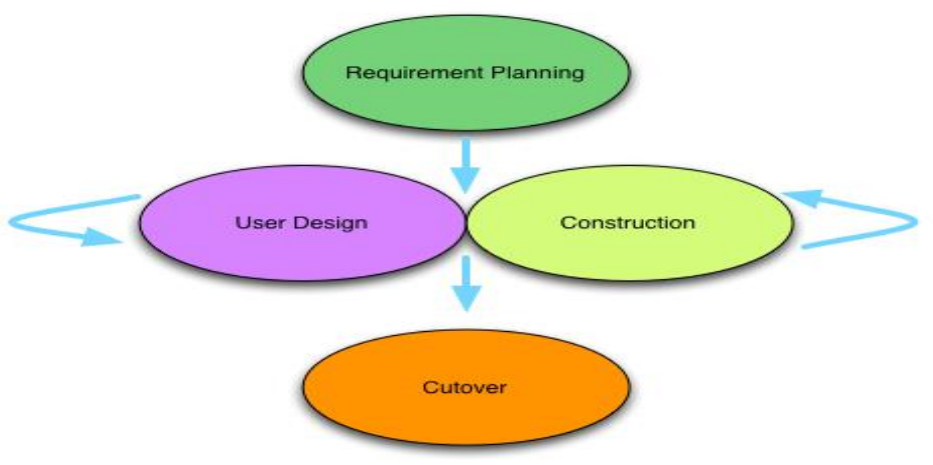

\section{B. System Prototype User Design (UD) Phase}

- Process Model

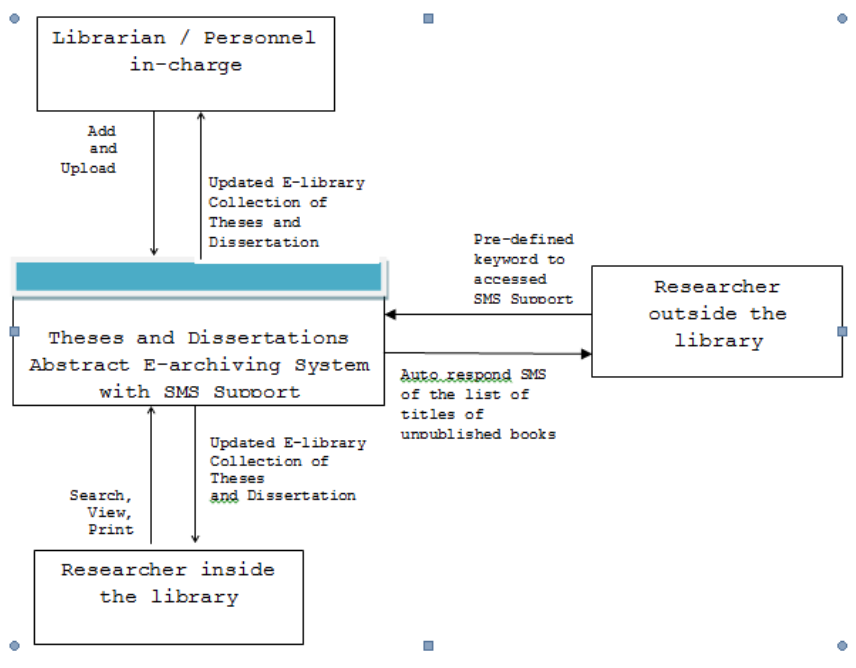




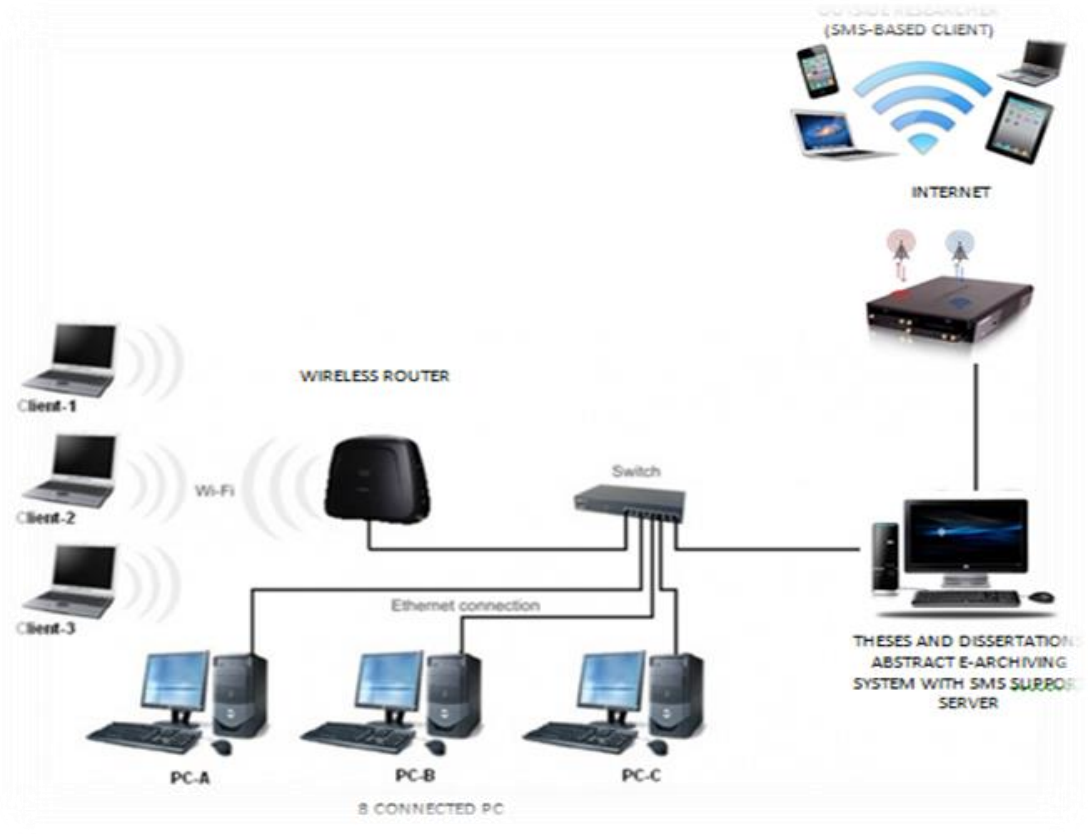

\section{RESULTS AND DISCUSSION}

The present investigation has the following findings:

1. The results of the developed system are 4.81 which is interpreted as Very Good.The findings implied that the degree in which the functions facilitate had accomplished the specified tasks and objectives of the developed system of the specified users in searching and archiving the abstract of their related study. The SMS Manager as the third party plays a vital role as SMS support which provides and respond to such request, through an auto-responses send back dynamic replies based on specified keywords to the inquiries is operational and accessible to outside researchers.

2. The usability of the developed features of Theses and Dissertations Abstract E-Archiving System with SMS Support have a computed mean of 4.82 which is interpreted as Very Good. The findings implied that the degree in which using the features of Theses and Dissertations Abstract E-Archiving System with SMS Support can be used by specified users to achieve specified goals with effectiveness, efficiency, freedom from risk and satisfaction in a specified context of use.

Features are easy to operate and control, reports generated by the system such as collection views and SMS logs can be easily viewed, retrieved and printed in real-time by the Librarian. Also, it reduces hours spent in retrieving archives of theses and dissertations.

3. The performance of the developed system in terms of functionality, reliability and efficiency have the computed mean of 4.82 interpreted as Very Good. This simply implied that the degree in which the response and processing time throughput rates of the system, in performing its functions, meet the requirements by using the developed Theses and Dissertations Abstract E-Archiving System with SMS support is very good.

It provides borrowers with real-time information for the researchers using wired and wireless network which can be easily archive and select the related literature they need. The developed system is useful in minimizing the time for the researchers and provide better services. Control and security of the developed system indicate secure and safe. Wherein all the abstract of Theses and Dissertations can be viewed and downloaded in jpeg format for the author's protection by copyright and IPR Law.

\section{CONCLUSIONS}

Based on the interpretation that was discussed in the preceding chapter, the following conclusions arrived:

1. The developed Theses and Dissertations Abstract E-archiving System with SMS Support based on the result and findings of surveys, electronic archiving of theses and dissertations were accessible in real-time. The two-way SMS provider and autoresponse send back dynamic replies based on specified keywords to the inquiries was operational and accessible for outside researchers are users friendly and fully functional.

2. The usability of the feature of the developed system is operational and accessible with effectiveness and efficiency was appropriate for the need of the users. The specified goals are easy to operate and control in which the design interface enables the pleasing and satisfying interaction for the users. 


\section{Theses and Dissertations Abstract E-Archiving System with SMS Support}

3. The performance of the developed system and the processing time throughout rates meet the end-users requirements. The degree in which a developed system can perform its required functions efficiently while sharing a common environment and resources with the other products, without detrimental impact on any other product.

\section{REFERENCES}

1) Andrew, T. (2014). "Intellectual property and electronic theses. JISC Legal Information Service”. Retrieved on May 27, 2016, from http://www.era.lib.ed.ac.uk/retrieve/1319/IP_etheses.pdf

2) Beaven, J. (2014). "Digital dissertations. American Libraries". Retrieved on August 1, 2016, from http://www.sciencedirect.com/science/article/pii/S1877042811001509

3) Grigorova, S. (2010). "The Elusive Quest: Software Product Quality Evaluation" Retrieved on August 1, 2016, from https://macsphere.mcmaster.ca/bitstream/11375/8980/1/fulltext.pdf

4) Olaleye1, O., Olaniyan, A., Eboda, O., and Awolere, A. (2013). "SMS-Based Event Notification System. Journal of Information Engineering and Applications" ISSN 2224-5782 ISSN 2225-0506 Vol.3, No.10,

5) Rodriguez, K. (2016). “Electronic Theses \& Dissertations (ETDS)A Literature Review”. Retrieved on June 2, 2016, from http://www.academia.edu/912556/ELECTRONIC_THESES

6) Signori, B. (2014) "e-Diss.ch : collecting and archiving online theses at the Swiss National Library National Universities commission, National virtual library". Retrieved on May 28, 2016, from African Studies Companion Online. doi:10.1163/_afco_asc_3038

7) Singh, P. K. and Kumar, R. (2011). "Automatic Response System Using SMS". International Journal of Engineering Research and General Science 2(2)Feb-Mar 2014 ISSN 2091-2730 